\title{
A LINGUA GALEGA NO MUNDO: PROXECCIÓN EXTERIOR, INVESTIGACIÓN E ENSINO
}

\author{
GALICIAN LANGUAGE THROUGHOUT THE WORLD: \\ EXTERNAL PROJECTION, RESEARCH AND TEACHING
}

Valentín García Gómez ${ }^{1}$ Secretario xeral de Política Lingüística da Xunta de Galicia

\section{INTRODUCIÓN}

As identidades colectivas, coma as individuais, constrúense, en non pouca medida, á luz da mirada que sobre elas proxectan os ollos alleos. Neste sentido, identidade e alteridade son, por moi antitéticos que semellen, dous conceptos estreitamente ligados e mesmo complementarios. Esta é a razón pola que os Estados se esforzaron dende sempre e se esforzan hoxe aínda con maior empeño en influír positivamente na conformación desa mirada do outro. Por

\footnotetext{
1 sxpl.secretaria@xunta.gal
} 
resultaren obvios os porqués, talvez non cumpra insistir en que, historicamente, só os Estados - entidades políticas que contaban con auténticas estruturas de poder - posuíron a capacidade de levar a cabo plans e proxectos desta natureza. Non foron alleas a este cometido as accións diplomáticas e consulares, nin tampouco a creación ad hoc de organismos oficiais destinados a configuraren e «venderen» unha imaxe de país entre os cidadáns doutros Estados, unha tarefa interventora que, por outra banda, se realizou case sempre a través da difusión daquelas expresións e valores culturais máis estandarizados. Neste sentido, a ninguén lle resultarán estraños, certamente, nomes coma o British Council ou a Aliance Française, e, referíndonos agora a dous organismos máis próximos aos galegos e galegas cultural e xeograficamente, o Instituto Camões ou o Instituto Cervantes, este último actualmente de celebración pois cumpre 30 anos de andadura dende a súa creación en 1991. Hoxe en día, persiste esta tendencia, como se pode apreciar na emerxencia das denominadas marca-país, ás que os Estados lles dedican abundantísimos recursos.

Galicia careceu de calquera órgano de poder institucionalizado nos seus moitos séculos de historia ata a aprobación do seu Estatuto de Autonomía en 1981, feito que supuxo a semente para a creación, hai exactamente agora 40 anos, de institucións propias tan importantes como o Parlamento de Galicia. Por tal motivo, o labor da defensa e difusión dos valores culturais de Galicia fóra das súas fronteiras físicas tivo que ser asumido ata a década de 1980, maioritariamente, por entidades e persoas da emigración, sen que as asistira ningunha institución gobernativa. Paga a pena traer aquí o exemplo senlleiro da Asociación Iniciadora e Protectora da Academia Galega, fundada, en xuño de 1905, polo egrexio Xosé Fontenla e Leal e outros insignes emigrantes galegos en Cuba, como o poeta Manuel Curros Enríquez. Sabían aqueles promotores da aínda inexistente Real Academia Galega que a lingua e a cultura de Galicia 
precisaban de organismos que tanto dentro coma fóra do país as defendesen e proxectasen máis alá do ámbito xeográfico que lles era propio, e, con tal propósito, promoverán a constitución da devandita institución académica na Coruña e, ademais, algúns deles propoñerán crear unha Cátedra de Lingua Galega en Madrid.

Este constitúe, certamente, un exemplo sobranceiro, pero poderíanse traer aquí varios centos máis, algún dos cales deberían quedar escritos en letras de ouro, tal é o caso do protagonizado polo egrexio artista Luís Seoane, quen durante as décadas de 1940 e 1950 se empeñou en divulgar a cultura de Galicia na Arxentina a través dunha intensa actividade editorial que tiña por destinatarias non só ás xentes que integraban a colectividade galega emigrante senón tamén á restante cidadanía arxentina non vinculada a Galicia. Por moi querida por min, non podo deixar de citar a esforzada e quixotesca empresa denominada Editorial Follas Novas que Xosé Neira Vilas e mais Anisia Miranda poñen a andar, en Bos Aires, en xullo de 1957, co obxecto de promocionaren a literatura e o libro galegos en América do Sur. Tales iniciativas debéronse na maioría dos casos ás virtudes humanas e ao galeguismo de persoas como Xosé Neira Vilas, quen decidiu, axudado por Anisia Miranda, dar un paso á fronte co seu proxecto editorial despois de case dúas décadas de emigración ininterrompidas.

Na maioría dos casos estas iniciativas individuais e os seus logros eran sentidos e celebrados coma un éxito colectivo. Ocorreu así cando o 12 de abril de 1925 aparece o artigo «Momento actual de la poesía gallega. Los precursores» no suplemento dos domingos de La Nación. Era a primeira colaboración do emigrante Eduardo Blanco-Amor neste prestixiosísimo xornal arxentino, á que lle seguirían, nos tres seguintes meses, outros tantos artigos de temática cultural galega, feito que era para el un premio como periodista, pero que constituía, por enriba de calquera outra consideración, unha fazaña para a 
comunidade galega, que vía como se prestixiaba deste xeito a cultura do seu país, tantas veces menosprezada e mesmo insultada no de acollida. Fóra do ámbito arxentino, é digna de mención, neste sentido, a creación en Ciudad de México, en 1953, do Patronato da Cultura Galega co fin de espallar e dar a coñecer a cultura galega na sociedade mexicana.

Pero como dixen máis arriba, trala aprobación do Estatuto de Autonomía en 1981 o noso país foise dotando de institucións e organismos que teñen entre os seus obxectivos a proxección exterior dos valores culturais de noso. Cómpre recordar, por citar un caso, a creación, en 1983 -polo tanto de forma case parella á instauración da Autonomía-, do Consello da Cultura Galega, cuxa área de Acción Exterior ten como obxectivo difundir a realidade e a especificidade galega no mundo. Por aqueles anos créase, asemade, o primeiro departamento de política lingüística no aínda nacente goberno autonómico da Xunta de Galicia, departamento de promoción da lingua galega que, dende a súa etapa inicial, tivo na acción exterior unha das súa principais liñas de acción, primeiro entre as colectividades emigrantes espalladas polo mundo, e, seguidamente, tamén fóra deste ámbito. Isto foi así porque se sabía que, no proceso de reversión da consideración nada amable que existía da lingua galega na propia Galicia, era condición indispensable a restitución dunha mirada amable entre xentes propias e alleas.

Neste senso, pénsese que o chamado proceso de normalización levado a cabo en Galicia nos últimos 30 anos consistiu, basicamente, na conquista dun recoñecemento social para a lingua galega. Sei que isto supón unha afirmación reducionista acerca dun proceso moi complexo, pero non é menos certo que, á fin e ao cabo, foi iso, a loita por conquistar un prestixio e unha posición social na Galicia de hoxe para o galego, o que determinou a maior parte das políticas lingüísticas levadas a cabo no noso país. Daquela cumpría tamén conquistar o prestixio entre a comunidade galega emigrante, labor que se levou a cabo a 
través de múltiples iniciativas, non sendo a menor delas a organización de centos de cursos de lingua e cultura galegas.

\section{REDE DE LECTORADOS E DE CENTROS DE ESTUDOS GALEGOS}

A posibilidade de estudar a lingua e a cultura de Galicia en universidades de América, de Europa e de España é unha realidade consolidada que leva contribuído de maneira fundamental á difusión do galego no exterior, á investigación lingüística desde perspectivas moi diversas e tamén ao prestixio da lingua entre os seus propios falantes, ao observaren o interese e o recoñecemento que posúe fóra das fronteiras administrativas de Galicia.

Na actualidade, o galego é obxecto de estudo en 35 universidades de 17 países de América e Europa (incluída España), en cada unha das cales está asentado un Centro de Estudos Galegos e vinte e sete delas contan cun lectorado. Nestas universidades impártense materias de lingua, literatura e cultura galegas adaptadas ás necesidades do alumnado de cada lugar concreto (gramática histórica, cursos de conversa, cursos de lingua e civilización etc.). Asemade, numerosas actividades relacionadas coa lingua galega e, en xeral, co patrimonio de Galicia complementan os programas formativos.

Están asentados en 19 países de Europa e América con esta distribución:

$>$ En Europa (29 universidades): 4 en Alemaña, 1 en Croacia, 9 en España (fóra de Galicia), 1 en Finlandia, 1 en Francia, 1 en Hungría, 3 en Italia, 1 en Irlanda, 1 en Polonia, 3 en Portugal, 2 en Reino Unido, 1 en Rusia e 1 en Suíza.

$>$ América (6 universidades): 4 en Brasil, 1 en Cuba e 1 en UEA. 


\section{A APRENDIZAXE DE GALEGO PARA ESTRANXEIROS EN GALICIA}

Xa transcorreron 26 anos dende que o Instituto da Lingua Galega e a Real Academia Galega, en colaboración co departamento de Política Lingüística da Xunta de Galicia, organizaron a primeira edición dos Cursos de verán de lingua e cultura galegas para estranxeiros. A estes cursos viñéronse sumar, anos despois, os organizados polas universidades da Coruña e de Vigo. Nos tres casos o fin primordial dos cursos é darlle ao alumnado asistente a oportunidade de familiarizarse coa lingua galega e coa realidade sociocultural de Galicia. Amais das clases de lingua, prográmanse leccións sobre literatura, historia, xeografía, arte etc., de Galicia, así como visitas a lugares de especial interese cultural. Para facilitarlles a súa estadía en Galicia, en numerosos casos concédenselles aos alumnos e alumnas bolsas de axudas de custos. Tal é o éxito destes cursos que mesmo se pode falar da existencia de varias xeracións de persoas amantes de Galicia, con profundos vencellos co noso país, que recibiron a semente de galeguidade nestas aulas.

\section{ESTADÍAS EN GALICIA PARA INVESTIGADORES}

O Centro Ramón Piñeiro para a Investigación en Humanidades, dependente igualmente da Secretaría Xeral de Política Lingüística da Xunta de Galicia, está encargado de promover, desenvolver e dar difusión a proxectos e programas galegos de estudos lingüísticos, literarios, históricos e antropolóxicos. Para a consecución dos seu obxectivos desenvolve un nutrido número de proxectos, que van dende a historia da lingua e da literatura ata as tecnoloxías da información e da comunicación, nas que participan novos investigadores, moitos deles procedentes de lugares ben afastados xeográfica e culturalmente do noso. Para iso fai, anualmente, un concurso público de bolsas 
de formación en proxectos relacionados coas investigacións que se están a desenvolver no Centro.

\section{OUTRAS INICIATIVAS}

\subsection{O galego na Unión Europea}

O galego é hoxe unha lingua con presenza en institucións internacionais, o que permite comunicar de maneira oficial os nosos intereses individuais e colectivos a través da lingua propia.

O galego está, desde finais de 2005, presente nas institucións europeas. O seu uso xa é oficialmente un feito no Comité de Rexións. O Parlamento Europeo aprobou a utilización das linguas cooficiais de España, entre elas o galego, nas comunicacións dos cidadáns co Parlamento Europeo. Os acordos tamén permiten o uso do galego no Consello de Ministros da Unión Europea e na Comisión Europea. Desde o 26 de outubro de 2007 figuran na web da Comisión Europea informacións en galego na sección de novas dos Estados membro.

Por orde cronolóxica, estas son as institucións europeas que posibilitan o emprego das linguas cooficiais nas condicións fixadas polo Consello:

> Comité das Rexións (acordo de 16 de novembro de 2005)

$>$ A Comisión Europea (acordo de 21 de decembro de 2005)

> O Consello de UE (17 de febreiro de 2006)

> Comité Económico e Social Europeo (7 de xuño de 2006)

> Parlamento Europeo (3 de xullo de 2006)

$>$ Valedor do Pobo Europeo (20 de novembro de 2006)

> Tribunal de Xustiza das Comunidades Europeas (acordo de 27 de abril de 2009) 
Os cidadáns e cidadás que desexen dirixirse en galego ao Valedor do Pobo Europeo (Ombudsman) tamén o poden facer nesta lingua, en virtude da entrada en vigor dun convenio entre España e este organismo comunitario. A introdución do galego na Unión Europea é un recoñecemento ao plurilingüismo natural dos países que a integran. O certo é que algunhas das linguas cooficiais dos estados ou linguas minoritarias contan cun número de falantes maior ca outras oficiais, e mesmo cun status semellante dentro dos seus territorios. A Constitución española de 1978 permite o recoñecemento da cooficialidade doutras linguas diferentes ao español dentro do Estado.

Os cidadáns e as cidadás de Galicia que se dirixan aos órganos europeos que os representan poden usar tamén o galego para esas comunicacións e teñen dereito a recibiren contestación nesta lingua.

\subsection{O galego nas comunidades galegas de emigrantes}

En cooperación con outras entidades, e mais coa Secretaría de Emigración, a Secretaría Xeral de Política Lingüística da Xunta de Galicia promoveu, durante décadas, cursos de lingua e cultura galegas, impartidos por profesores graduados en Filoloxía Galega, e que contaron tamén cunha certificación oficial expedida en Galicia. Sempre foi unha prioridade ofrecerlle ao numeroso colectivo de emigrantes galegos e aos seus descendentes a posibilidade de afondar no estudo da súa lingua primeira e, a través dela, manter un contacto coa realidade da sociedade e da cultura das súas orixes. A rede de centros galegos e casas de Galicia espalladas polo mundo era e é unha estrutura ampla e estable para acoller esa formación. Así mesmo, a Secretaría Xeral de Política Lingüística ten convenios no Reino Unido, co colexio Vicente Cañada Blanch de Londres, e tamén na Arxentina, onde o Colexio Santiago Apóstolo de Bos Aires ofrécelle ao seu alumnado a posibilidade de aprender 
galego en todos os cursos, desde a etapa preescolar ( 3 anos) ata o nivel secundario ( $1^{\circ}$ de bacharelato). O número de alumnos que estudan galego neste centro é actualmente superior aos 400, que asisten ás materias de Lingua e Literatura, Xeografía e Historia de Galicia.

Neste mesmo ámbito, convén mencionar tres iniciativas implementadas máis recentemente. Referireime, en primeiro lugar, á incorporación no Colexio Castelao de Caracas de aulas (así como doutras actividades) que teñen por obxecto divulgar o coñecemento do idioma propio e da cultura de Galicia entre o alumnado do centro educativo. Digna de mención é, igualmente, a posta en marcha da Aula GaliciaAberta por parte da Secretaría Xeral da Emigración co propósito de manter a actividade formativa e divulgativa da cultura galega en todo o mundo durante o período de pandemia por coronavirus. Dentro desta oferta formativa atópase a Aula de lingua e cultura galegas, coa que se persegue continuar o proceso de adquisición e consolidación do coñecemento do idioma galego por parte das galegas e galegos non residentes en Galicia. Por outra banda, convén dar noticia dos tres cursos Cultura Galega e Emigración: A Galeguidade na Diáspora. Trátase duns cursos que teñen por obxectivo abordar o mapeado cultural galego na emigración, con todo o que este achegou tanto aos países de acollida como a Galicia.

Por último, cómpre referir que tamén existe a posibilidade de estudar galego nalgúns centros do Instituto Cervantes como que na comunidade de Castilla y León existen áreas galegofalantes que ofrecen a posibilidade de estudar galego no ensino regular.

\subsection{Rede europea para a promoción da diversidade lingüística}

No dominio dos Estados membros da Unión Europea fálanse na actualidade, ademais das linguas consideradas oficiais polo Consello de 
Europa, máis dunha trintena de linguas denominadas «rexionais ou minoritarias», distribuídas en corenta e oito grupos lingüísticos. Máis de 20 millóns de cidadáns da Unión falan algunha destas trinta e seis linguas. Non é de estrañar, polo tanto, que a chamada cuestión lingüística suscitara, desde sempre, un grande interese no seo da Unión Europea. Como é sabido, o Parlamento Europeo elixiuse por primeira vez en 1979 e, dous anos despois, a asemblea de Estrasburgo adoptou a súa primeira resolución nesta materia, redactada por Gaetano Arfè. Esta contiña dous conxuntos de propostas. En primeiro lugar, a resolución solicitaba dos gobernos nacionais e autoridades rexionais e locais unha política a favor das linguas minoritarias nos ámbitos da educación e dos medios de educación de masas, así como no eido da vida pública e das políticas sociais. A incorporación de novos Estados membro supuxo un aumento do número de linguas oficiais ás que se lles outorgou a condición de linguas oficiais na Unión Europea.

Dentro deste marco de referencia, creouse durante o ano 2008, tras varias reunións preparatorias nas que participou a Xunta de Galicia, a Network to promote Linguistic Diversity (NPLD), un proxecto no que están integradas institucións académicas, organismos de diferente natureza e gobernos rexionais e nacionais de diferentes países europeos dedicados á promoción, ao ensino e á promoción social de linguas minoritarias. O obxectivo fundamental da NPLD é a cooperación e intercambio mutuo de experiencias, así como a promoción da diversidade lingüística no marco da Unión Europea.

Galicia integrouse na NPLD como membro de pleno dereito desde a súa fundación e forma parte do seu comité executivo. 


\subsection{O galego e a lusofonía}

Para a Galicia ilustrada e consciente, a lingua portuguesa nunca deixou de percibirse e sentirse como parte da mesma entidade, pero á que se invocou na maior parte dos casos apelando aos tempos idos, nomeadamente á Idade Media. Esta forma de ver as cousas, de raíces netamente culturalistas e historicistas, mudou a partir da década de 1950 grazas á contribución, de entre outros intelectuais, de Valentín Paz-Andrade, quen foi a primeira voz que avisou sobre as potencialidades e a utilidade da lingua galega grazas á emerxencia económica de Brasil que el anunciaba hai seis décadas. De xeito sumario, el afirmaba o seguinte en 1959: «Galicia é fonte, Portugal, ponte, e, hoxe, o Brasil, algo que se asemella ao paraíso prometido». Nesta liña, débese citar a chamada Lei Paz-Andrade, ao abeiro da que se impulsou a lingua portuguesa como materia de estudo no sistema educativo galego non universitario en 2013. Oito anos despois, as expectativas estanse a cumprir máis alá mesmo do agardado, o que se debeu á grande aceptación que tivo o proxecto na comunidade educativa. 